\title{
Recurrent Giant Cell Tumor of the Distal End Radius: A Case Report and Surgical Treatment with Wide Resection and Reconstruction with Non-Vascularised Autologous Proximal Fibular Graft
}

\author{
Venkatesh Gupta, Vijaya Kumar \\ Department of Orthopaedics, Mamata Medical College, Khammam, India \\ Email: veegee 47@gmail.com, chiruvellav@gmail.com
}

Received 8 September 2014; revised 24 October 2014; accepted 7 November 2014

Academic editor: T. M. Wong, Department of Orthopaedics and Traumatology, The University of Hong Kong, China

Copyright (C) 2014 by authors and Scientific Research Publishing Inc.

This work is licensed under the Creative Commons Attribution International License (CC BY).

http://creativecommons.org/licenses/by/4.0/

c) (i) Open Access

\begin{abstract}
Giant cell tumour of the distal radius is the 3rd most common site after proximal tibia and distal femur. It is locally aggressive and is associated with a high rate of recurrence. Although it is usually treated with various modalities of treatment, wide resection and reconstruction with proximal fibular autograft is most commonly accepted in recurrent cases. The following is a case report of such a case with surgical management.
\end{abstract}

Keywords

Giant Cell Tumor, Recurrence, Distal end Radius, Fibular Bone Graft

\section{Introduction}

Giant cell tumor is a benign bone tumor, and usually affects young adults. It is locally aggressive with tendency for local recurrence [1]. 10 percent of these lesions appear in distal radius. This is the 3 rd commonest site for this tumor after proximal tibia and distal femur [2] [3].

The problem of selecting proper treatment is complicated by the failure of its histologic appearance to indi- 
cate its biologic behavior [4]. The goals of treatment are to achieve satisfactory removal of the tumor, to decrease the chances of local recurrence and to preserve as much wrist function as possible. Treatment options are 1) curettage alone or with bone grafting; 2) curettage of the tumor and packing of the cavity with methyl methacrylate or 3) resection of the lesion followed by reconstruction.

Although curettage and bone grafting can preserve the joint functions, it has been associated with local recurrence rate of $27 \%-54 \%$ [5]. A low rate of recurrence has been noted after resection of the lesion, but a complex reconstruction procedure (arthroplasty) or arthrodesis of the wrist is required. Other procedures that may be employed to reconstruct the defect include vascularised or non-vascularised bone graft from tibia or proximal fibula, osteo-articular allograft [6] and transposition of corpus [7]. All these procedures have certain morbidity and complications associated with them, nevertheless, resection and reconstruction may be the only option in case of aggressive tumor, which erodes the cortex.

Walthar (1911) was the first to describe the use of a free non-vascularised proximal fibular graft to replace the resected distal radius [8]. Most of the authors have reported various success rates with the procedure. The purpose of the study is to report a giant cell tumor of the distal end radius which is recurred after 6 months of curettage and cancellous bone grafting and subsequent treatment with wide resection and reconstruction with autologous non-vascularised proximal fibular grafting with satisfactory result.

\section{Case Report}

This is a 40-year-old male patient, who was apparently asymptomatic until 1 year back. Then he gradually developed pain and swelling over dorsal aspect of left wrist. Pain which is dull in nature, not radiating, aggravated with wrist movements and relieved with rest. Swelling gradually increasing in size. On examination, swelling present over distal end radius, no local rise of temperature, no crepitus, tenderness present, movements are painful at the wrist.

Not associated with any other co-morbidities.

Then we take anteroposterior and lateral X-ray radiograph (Figure 1) of the wrist which revealed an expanded osteolytic lesion at the epiphyseal region of the distal radius. Then we took FNAC which had given an impression of giant cell tumor. Then we did curettage and autologous cancellous bone grafting from ipsilateral iliac crest. Sample sent for biopsy which confirmed the diagnosis. Figure 2 shows the immediate post-operative radiograph.

Then he came for regular follow-up at 1st, 2nd, 3rd and 6th months. At 6th month follow-up we again noticed a swelling at the same region, which is also gradually increasing in size. Figure 3 shows X-ray AP and lateral views of wrist with resorption of previous cancellous graft in distal radius, bone cortex was thinned and ballooned, and there was a cortical breach. Then we have taken MRI. MRI of wrist (Figure 4) shows well defined lytic lesion in the distal end of the radius measuring $3.3 \times 4.8 \times 2.9 \mathrm{~cm}$ which is homogenous hypointense on T1 and T2. A radiological diagnosis of giant cell tumor Campanacci grade 3 was made [9].

He subsequently underwent a wide excision of distal end of the left radius and ipsilateral autologous non-vascularised proximal fibular grafting. Biopsy Sample sent which confirmed the diagnosis of Giant cell tumor of the distal radius. Figure 5 dipicts Haematoxylin and Eosin staining of the sample smear showing features of Giant cell tumor of bone with areas showing storiform pattern and sheets of histiocytes under light microscope [10]. Figure 6 shows Anteroposterior (a) and lateral (b) view of left wrist after immediate post operative period.

\section{Operative Procedure}

The surgery was performed in 3 stages.

\subsection{Harvesting of Autologous Non-Vascularised Fibular Graft}

Tourniquet applied on the ipsilateral thigh. A Posterolateral incision is made along the proximal half of the fibula and curved medially toward popliteal fossa. The common peroneal nerve is identified and protected. The plane between the lateral head of the gastrocnemius and the soleus is entered. The fibula bone is exposed and carefully dissected. $7 \mathrm{~cm}$ length of the fibula is been exposed, it is osteotomised. The distal end of the proximal fibula then is held using bone holder and intraosseous membrane is divided using scissor from distal to proximal to complete the excision.

\subsection{Resection of Tumor}

Tourniquet is applied on the left arm. An anterolateral incision is made along the distal third of left radius. The 


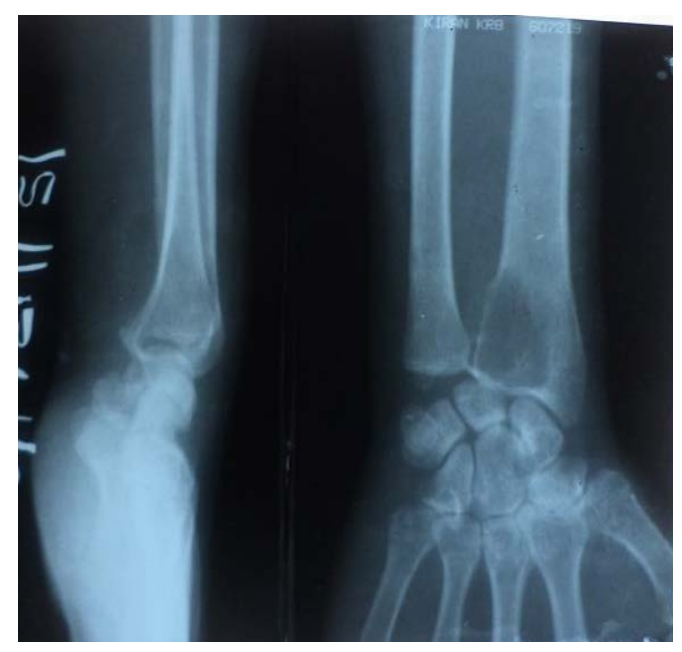

Figure 1. Pre-operative X-ray before curettage and bone grafting .

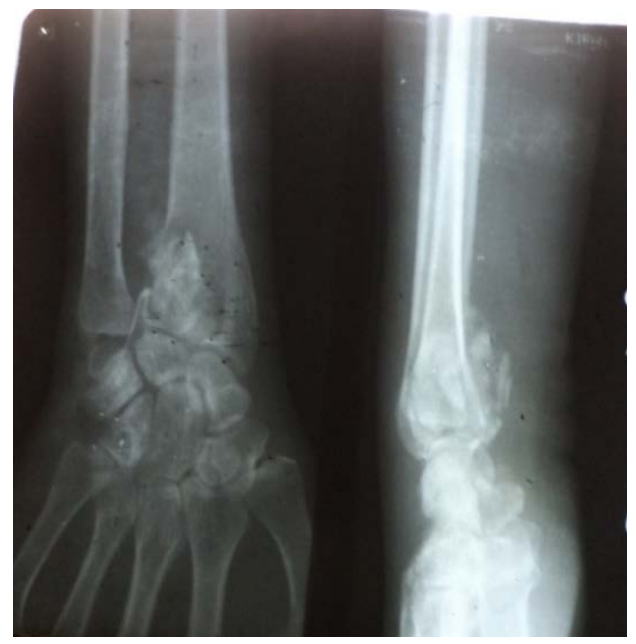

Figure 2. Post op X-ray after curettage and bone grafting.

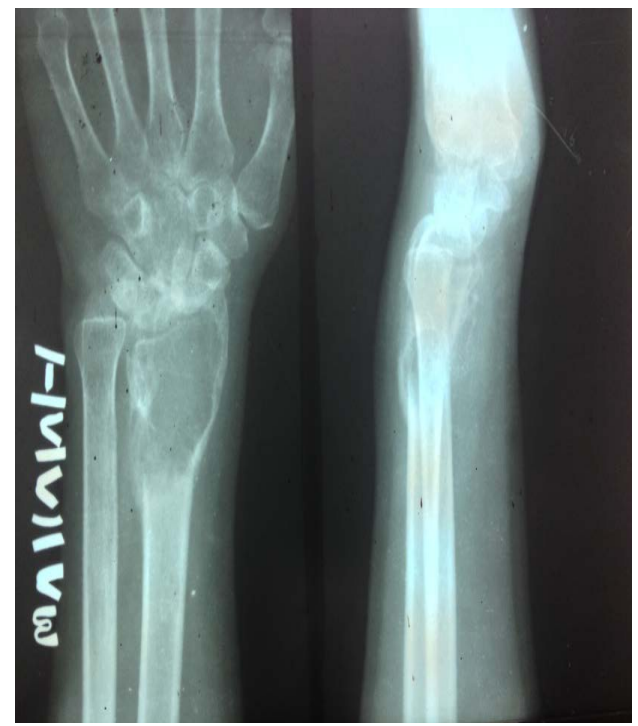

Figure 3. Follow up X-ray at 6 months showing recurrence. 


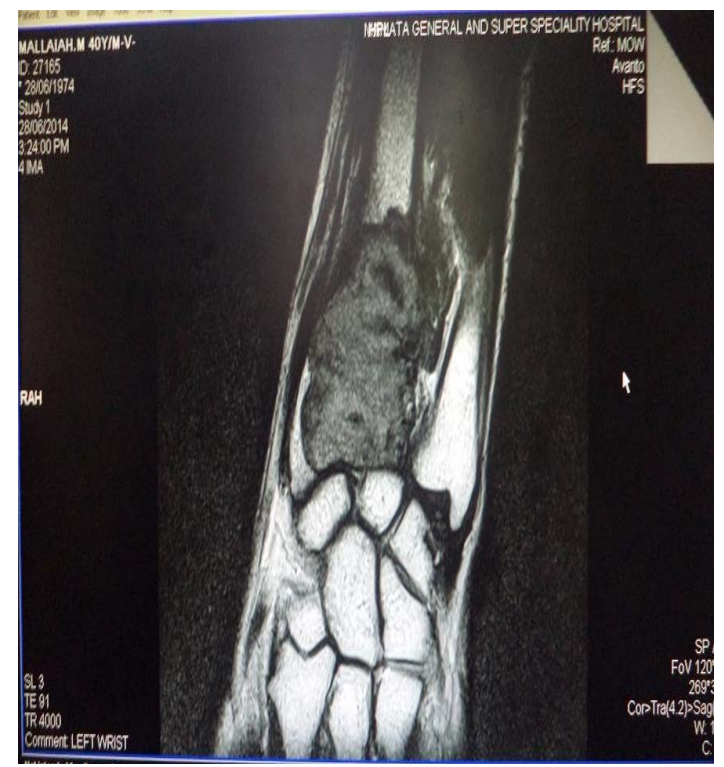

Figure 4. MRI picture showing recurrence.

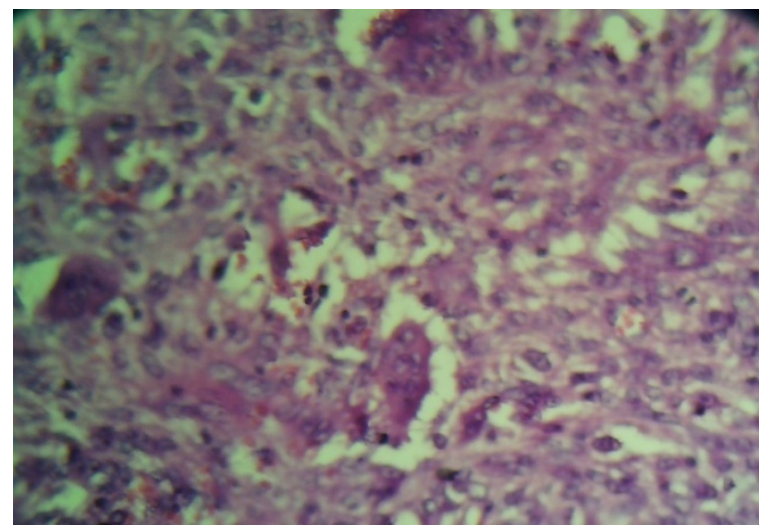

Figure 5. H/E staining of biopsy.

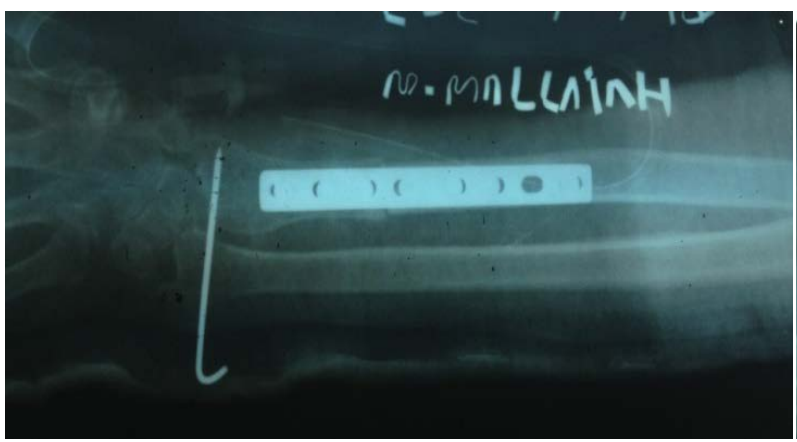

(a)

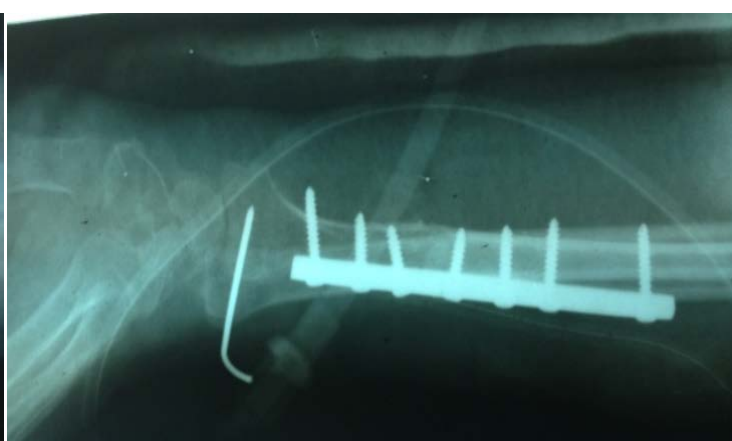

(b)

Figure 6. Immediate post op X-ray after excision and reconstruction with fibular grafting AP and Lateral views respectively.

radial artery is identified and protected. The dissection of the forearm muscles is carried out subperiosteally along the proximal part of the radius. The radius is osteotomised proximally. As the dissection is continued distally, the flexor tendons are separated from the distal radius with a good margin of healthy soft tissue including the Pronator Quadratus. For the dorsal dissection, the distal radius is grasped with Bone holder and lifted volarly and the extensor tendons are separated from the distal radius and only fibrous sheaths enclosing the extensor 
tendons are divided.

\subsection{Fixation of the Fibular Graft to the Wrist Joint}

The fibular graft is adjusted into the correct length in the wrist. To prevent subluxation of the wrist joint the fibula graft is placed in way that the carpal bones are well supported by the fibular head. The fibular head is in direct contact with the scaphoid and there should be no volar or dorsal subluxation. Dynamic compression Plating was done to secure the fibular graft to the remaining radius. A transverse $\mathrm{K}$ wire through the fibula and ulna is used for additional fixation and to help maintain the fibula and ulna in close approximation.

Wound is closed without tension and above elbow pop slab is applied.

Above elbow pop slab is applied for 6 weeks. Physiotherapy is commenced immediately after the surgery, starting with finger movements. Wrist physiotherapy is commenced at 6 weeks post surgery. Figure 7 shows left wrist X-ray antero posterior and lateral views at 4 weeks follow-up.

\section{Discussion}

Giant cell tumor of bone is locally aggressive and has a high incidence of recurrence [1]. It can also metastasize to the lung in less than 3\% cases. Ten percent of the giant cell tumor of bone involved the distal radius [2] [3]. They are recognized for variable behavior, which is not always related to radiographic or histological appearance [11]. Many authors reported that GCT of distal radius is particularly aggressive and has a high rate of local recurrence [12] [13].

The goal of treatment is to remove the tumor, decreasing the chances of recurrence and preserve the joint function. Different modalities of treatment have been advocated for giant-cell tumor of bone, including curettage, curettage and bone grafting, curettage and cryotherapy with liquid nitrogen of the cavity, curettage and application of phenol, curettage and insertion of methylmethacrylate cement in the cavity and resection followed by allograft, autograft or prosthetic reconstruction [14]. Simple curettage of giant-cell tumor is associated with a 5\% to $15 \%$ rate of local recurrence. Adjuvant treatment of bone bed with liquid nitrogen results in effective osteonecrosis to a depth of 1 to 2 centimeters. The extent of the osteonecrosis induced by liquid nitrogen is difficult to control, and thus it may weaken the bone and may cause a fracture. Malawar et al. observed a rate of recurrence of only $7.9 \%$ after cryosurgery in 102 patients with GCT [15].

Usage of Phenol as adjuvant therapy causes protein coagulation, damages DNA, and causes necrosis. It is toxic to the nervous system, the heart, kidney, and the liver. It is readily absorbable through skin, mucosa and open wounds.The technique of intralesional curettage followed by packing of the defect with methylmethacrylate(bone cement) has become popular. The free radicals and the thermal effects of the polymerization reaction can cause necrosis as much as 2 or $3 \mathrm{mms}$ in the cancellous bone. Additional advantages of the use of cement include ease to use, lack of donor-site morbidity, and elimination of the risk of transmission of disease associated with the use of allograft bone, immediate structural stability and potential for earlier detection of local recurrence.

This patient is having Campanacci grade 3 tumor [9]. This lesion is not amenable to curettage and adjuvant therapy, as it is already recurred. So techniques of athroplasty have been employed in an attempt to preserve motion at the wrist joint along with resection of the distal end radius. A lower rate of recurrence has been noted after resection compared with curettage, especially when the tumor has broken the cortex or a local recurrence. Eckardt et al. recommended en-bloc resection for most of the grade 3 lesions [1]. After resection, the defect has been reconstructed as an arthroplasty or an arthrodesis involving use of either vascularised or non-vascularised bone grafts from the tibia, the proximal part of the fibula, the iliac crest, or the distal part of ulna or prosthetic reconstruction. Other procedures that have been used to fill the defect have included use of an osteoarticular allograft [6] or custom-made prosthesis.

Although there are advantages to the use of vascularised bone grafts compared to non-vascularised bone graft, it may be less important in the distal radius, due to its relatively short length of resection and graft [16]. Vascularised fibular grafting has been reported to speed up the healing at host-graft junction, thereby reducing the period of immobilization, but dissection to obtain the fibula and its vascular pedicle and isolation of its recipient vessels requires meticulous attention [17]. Sophisticated infrastructure, skill, and prolonged operating time have made its use limited.

Wide resection with autologous fibular grafting offers several advantages like congruency of carpal joint, 


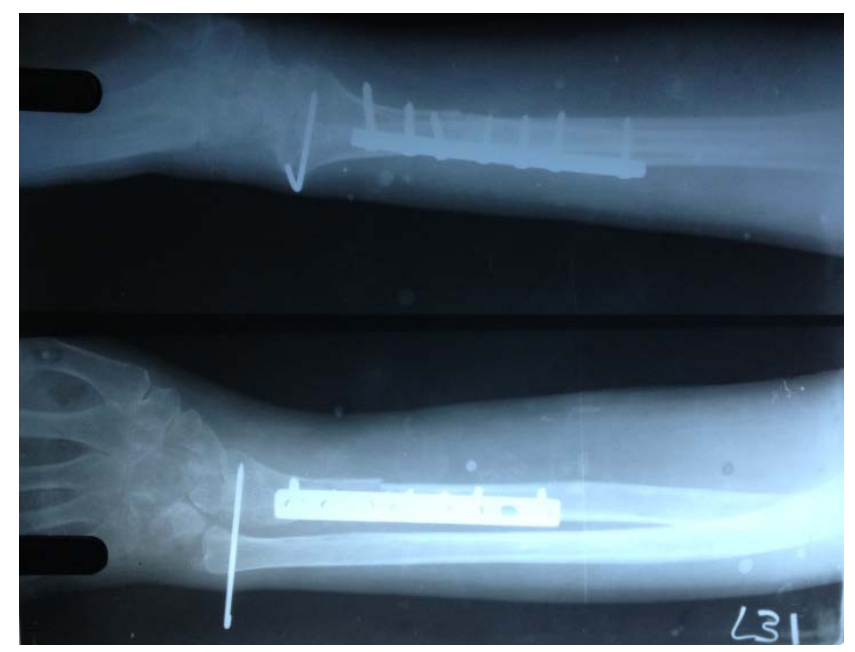

Figure 7. AP and Lateral views after 4 weeks of follow-up.

rapid incorporation as autograft, less structural change, and absence of immunogenic reactions, but it may carries the risk of complications related to the graft such as non union, graft fracture, residual subluxation of the carpus, degenerative oeteoathrosis, limited wrist movement and pain. There can also be donor site complicatins such as chronic leg pain, lateral ligament laxity, leg dysesthesia and foot drop. En-block resection of the giant cell tumor of the lower end radius is a widely accepted method for recurrent cases. Asavamongkolkul et al. reported good and excellent functional results in all seven patients of non-vascularised autologous fibular graft reconstruction [18].

En-bloc resection and reconstruction with non-vascularised autologous proximal fibular graft, internal fixation with dynamic compression plating and transfixation of fibular head with ulna and carpal bones minimizes the problem and gives satisfactory functional results [19].

\section{Consent}

The patient has given his informed consent for the case report to be published.

\section{References}

[1] Eckardt, J.J. and Grogan, T.J. (1986) Giant Cell Tumour of Bone. Clinical Orthopaedics and Related Research, 204, 45-58.

[2] Dahlin, D.C., Cupps, R.E. and Johnson Jr., E.W. (1970) Giant Cell Tumour: A Study of 195 Cases. Cancer, 25, 1061-1070. http://dx.doi.org/10.1002/1097-0142(197005)25:5<1061::AID-CNCR2820250509>3.0.CO;2-E

[3] Goldenberg, R.R., Campbell, C.J. and Bonfiglio, M. (1970) Giant Cell Tumour of Bone: An Analysis Two Hundred and Eighty Cases. Journal of Bone and Joint Surgery, 52, 619-664.

[4] Smith, R.J. and Mankin, H.J. (1977) Allograft Replacement of Distal Radius for Giant Cell Tumor. Journal of Hand Surgery, 2, 299-309. http://dx.doi.org/10.1016/S0363-5023(77)80131-7

[5] Campanacci, M., Baldini, N., Boriani, S. and Sudanese, A. (1987) Giant Cell Tumour of Bone. Journal of Bone and Joint Surgery, 69, 106-114.

[6] Clohisy, D.R. and Mankin, H.J. (1994) Osteoarticular Allograft for Reconstruction after Resection of a Musculoskeletal Tumour in the Proximal End of the Tibia. Journal of Bone and Joint Surgery, 76, 334-349.

[7] Vander Griend, R.A. and Funderburk, C.H. (1993) The Treatment of Giant-Cell Tumours of the Distal Part of the Radius. Journal of Bone and Joint Surgery, 73, 899-908.

[8] Walthar, M. (1911) Resection de extremite inferieure du radius pour osteosarcoma geffe de I extremite superiuete du perone. Sac Chir Par Bull Mem, 37, 739-747.

[9] Campanacci, M. (1976) Giant Cell Tumor and Chondrosarcoma: Grading, Treatment and Results. Recent Results in Cancer Research, 54, 257-261.

[10] Schajowicz, F. (1961) Giant-Cell Tumors of Bone (Osteoclastoma): A Pathological and Histochemical Study. Journal 
of Bone and Joint Surgery, 43, 1-29.

[11] Szendroi, M. (2004) Giant Cell Tumor of Bone. Journal of Bone and Joint Surgery (British Volume), 86, 5-12.

[12] O’Donnell, R.J., Springfield, D.S., Motwani, H.K., Ready, J.E., Gerhart, M.C. and Mankin, H.J. (1994) Recurrence of Giant Cell Tumours of Long Bones after Curettage and Packing with Cement. Journal of Bone and Joint Surgery (America Volume), 76, 1827-1833.

[13] Cheng, C.Y., Shih, H.N., Hsu, K.Y. and Hsu, R.W. (2001) Treatment of Giant Cell Tumour of the Distal Radius. Clinical Orthopaedics and Related Research, 383, 221-228. http://dx.doi.org/10.1097/00003086-200102000-00026

[14] Vander Griend, R.A. and Funderburk, C.H. (1993) The Treatment of Giant-Cell Tumors of the Distal Part of the Radius. Journal of Bone and Joint Surgery (America Volume), 75, 899-908.

[15] Malawer, M.M. and Dunham, W. (1991) Cryosurgery and Acrylic Cementation as Surgical Adjuncts in the Treatment of Aggressive (Benign) Bone Tumors: Analysis of 25 Patients below the Age of 21. Clinical Orthopaedics and Related Research, 262, 42-57.

[16] Hussain, P. and Singh, V. (2007) Giant Cell Tumor of Distal Radius: A Case Report and Description of Surgical Technique. The Internet Journal of Orthopaedics, 8 , Number 2.

[17] Pho, R.W. (1981) Malignant Giant Cell Tumour of Distal End of the Radius Treated by a Free Vascularized Fibular Transplant. Journal of Bone and Joint Surgery (America Volume), 63, 877-884.

[18] Asavamongkolkul, A., Waikakul, S., Phimolsarnti, R. and Kiatisevi, P. (2009) Functional Outcome Following Excision of a Tumour and Reconstruction of Distal Radius. International Orthopaedics, 33, 203-209. http://dx.doi.org/10.1007/s00264-007-0441-7

[19] Deb, H.K. and Das, N.K. (1992) Resection and Reconstructive Surgery in Giant Cell Tumour of Bone. Indian Journal of Orthopaedics, 26, 13-16. 
Scientific Research Publishing (SCIRP) is one of the largest Open Access journal publishers. It is currently publishing more than 200 open access, online, peer-reviewed journals covering a wide range of academic disciplines. SCIRP serves the worldwide academic communities and contributes to the progress and application of science with its publication.

Other selected journals from SCIRP are listed as below. Submit your manuscript to us via either submit@scirp.org or Online Submission Portal.
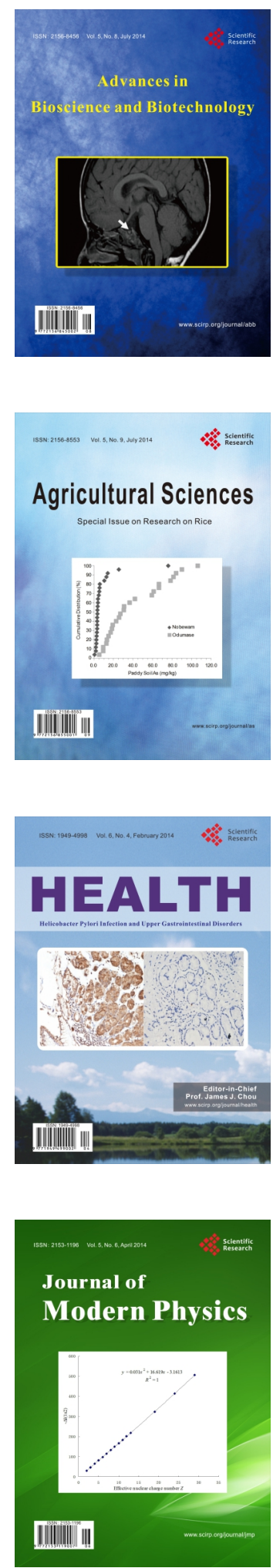
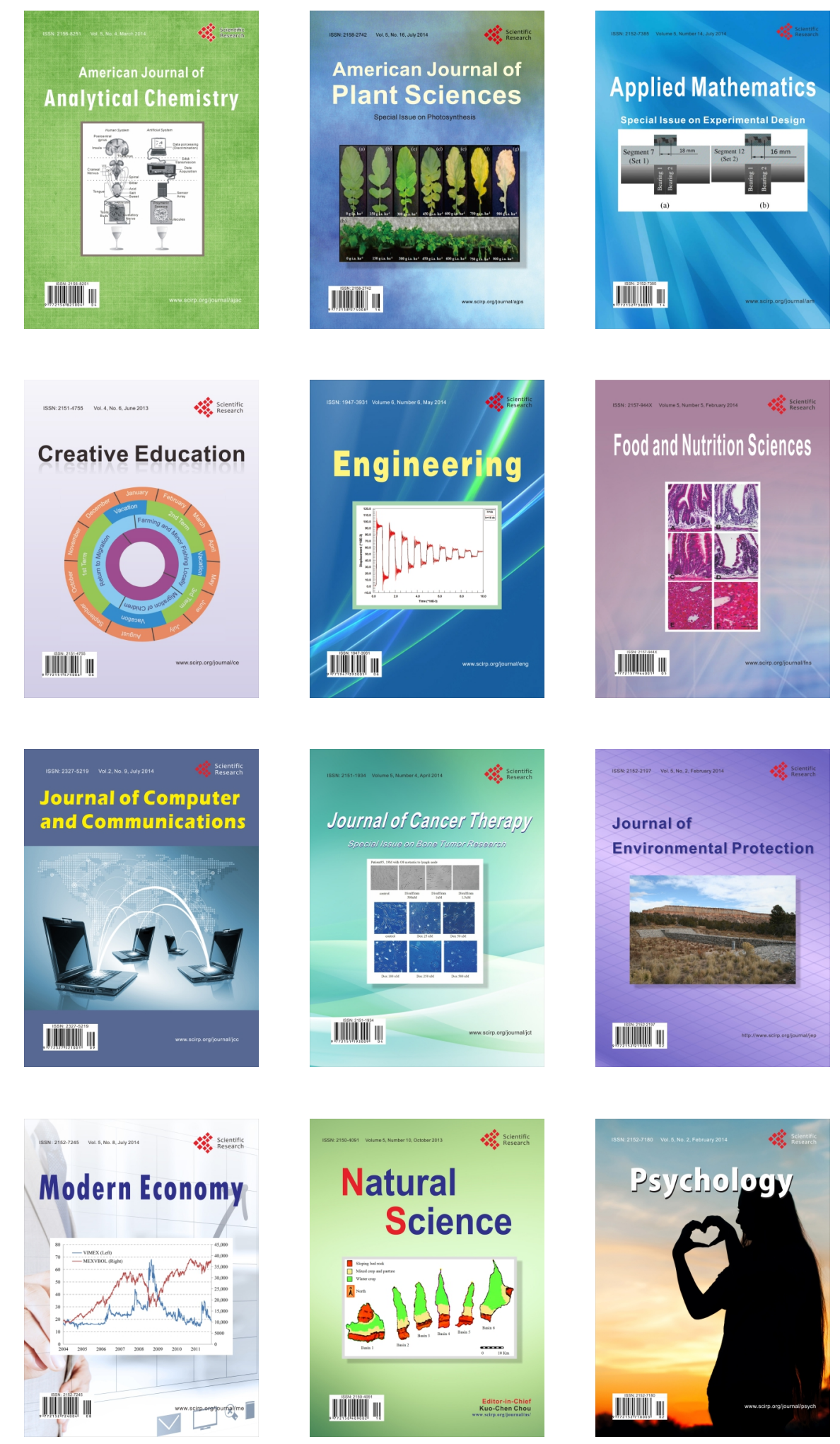